\title{
The Evolution of Industrial Clusters - Simulating Spatial Dynamics
}

\author{
Thomas Brenner ${ }^{\dagger}$ \\ Max-Planck-Institute for Research into Economic Systems \\ Evolutionary Economics Unit \\ Kahlaische Str. 10 \\ 07745 Jena, Germany \\ Niels Weigelt ${ }^{\ddagger}$ \\ Max-Planck-Institute for Research into Economic Systems \\ Evolutionary Economics Unit \\ Kahlaische Str. 10 \\ 07745 Jena, Germany
}

\begin{abstract}
$A B S T R A C T$. Industrial clusters have received much attention in economic research in the last decade. They are seen as one of the reasons for the economic success of certain regions in comparison to others. This paper studies the evolution of such industrial clusters. To this end, a spatial structure of regions is set up and the entry, exit, and growth of firms within these regions is modelled and studied with the help of simulations. We are able to obtain some knowledge about the basic characteristics of this dynamic process and about the spatial relation between industries that results. It is shown that it matters whether one or the other industry appears first and that location of clusters of one industry influence the location of other industries. Furthermore, some necessary conditions for the evolution of industrial clusters are identified.

KEYWORDS: evolution, industrial clusters, technological spillovers, simulations, spatial agglomeration.
\end{abstract}

$\dagger$ Author to whom correspondence should be addressed.

$\ddagger$ We want to thank Ulrich Witt, Guido Bünstorf and the participants of the 'Industrial District'-seminar and the workshop 'Economics Dynamics from a Physical View' for their helpful comments and discussions and the German federal ministry for education and research for financial support. The usual disclaimer applies. 


\section{Introduction}

Previously regional phenomenon have gained much attention within economics. Especially the question why certain regions are economically successful while others are not has been increasingly frequently discussed. The theoretical discussion of this phenomenon was triggered by various case studies of successful regions, like Silicon Valley, the Third Italy and many more (such case studies can, for example, be found in Rosegrant \& Lampe 1992, Saxenian 1994, and Dalum 1995). On the basis of these case studies several authors have attempted to explain the specific reasons for the success of each of these regions. Furthermore, some general concepts have been developed and various mechanisms have been identified that are seen as the causes for the success of those regions. The four main concepts are those of industrial districts, industrial clusters, innovative milieux and regional innovative systems (descriptions can be found in Becattini 1990, Maillat \& Lecoq 1992, Pyke \& Sengenberger 1992, Scott 1992, Camagni 1995, van Dijk 1995, Markusen 1996, Lawson 1997, Rabellotti 1997; an attempt to structure these approaches can be found in Brenner 2000).

Although the literature on industrial districts and the likes has increased and is still increasing tremendously, most of the literature addresses the reasons for the success of such regional systems and does not deal in general with the question, how these spatial structures come into existence. In most of the case studies this question is addressed for the specific situation of the region that is studied. In the case of Third Italy historical aspects that led to an entrepreneurial spirit, a trustful atmosphere and helpful politics are suggested to be the determinants (cf. Dei Ottati 1994 and Rabellotti 1997). In the case of Route 128 research funds from the Department of Defence are seen as the initial driving force (cf. Rosegrant \& Lampe 1992). While in the case of North Jutland a mixture of a wise creation of new institutes at the Aalborg university, the existence of a firm with experience in the relevant field and the change of the market are regarded to be the crucial factors for the evolution of this district (cf. Dalum 1995). Many other examples could be listed here - all with very specific explanations for specific developments.

The theoretical literature can be divided into two nearly separate strands. One is based on the above cited case studies and tries to identify general mechanisms that make local systems successful without considering the question of how these mechanisms started. The other is based on the empirical finding that economic activity, on a general and an industrial level, is concentrated (see for example the calculation of gini-coefficients in Krugman 1991a and the calculation of an index of geographic concentration in Ellison \& Glaeser 1994). With respect to the latter, several theoretical approaches have been able to rebuild concentration in simulations (cf. for example Camagni \& Diappi 1991 and Jonard \& Yildizoglu 1998). However, the aim of these studies was to obtain a structure of spatial distribution that is similar to the one observed in reality. They focus on the final distribution of economic activity. Thus, a theoretical approach that deals on a general level with the questions of how, where and when industrial clusters evolve is missing. This paper makes a first step to fill this gap. The major aim is to model the dynamics that lead to the evolution of industrial clusters. Through this, some first answers to the above questions are obtained. 
The approach proposed here is based on simulating the spatial dynamics of two industries using first a number of unconnected region. After the analysis of some basic aspects a cellular automaton is developed. This means that a twodimensional space is divided into small quadratic units. This allows to deal with local interactions, both within a unit and between neighbouring units. Similar approaches are used in the literature on economic agglomeration (cf. Camagni \& Diappi 1991, Krugman 1991b, Allen 1997a and 1997b, Schweitzer 1998, and Caniëls \& Verspagen 1999) and industrial concentration (cf. Jonard \& Yildizoglu 1998). However, the present approach deviates from these approaches in its aims and two structural aspects. The aim is to understand the evolution of industrially specialised regions in the context of a changing global environment. Instead of reproducing the distribution of economic agglomeration, this paper focuses on the change of the distribution of industrial activity and its path-dependency. To this end, two aspects have to be treated in more detail than it is done in the literature on agglomerations. First, the interaction between industries has to be explicitly modelled considering different courses of exogenous changes. Second, the processes within each geographical unit are modelled in detail, concerning the entry of firms, their growth and eventually their exit. The details of this are outlined in the next section.

The structural analysis by T. Brenner (2000) has shown that different mechanisms play a role during the evolution of an industrial cluster or milieu. Modelling all of them simultaneously would cause a simulation approach to be too complex to interpret the different results. Thus, it seem to be more adequate to restrict the modelling in each approach to one class of industrial cluster or milieu, so that the impact of each mechanism can be understood in detail. Finally the different mechanisms can be put together to get a comprehensive view of their complex interaction. This paper is restricted to two mechanisms. The first mechanism are knowledge spillovers between firms of the same and of different industries and the local stickiness of these spillovers (for empirical aspects on this see Jaffe, Trajtenberg \& Henderson 1992 and Audretsch 1998). The second mechanism are the local aspects of the founding of new enterprises. Both aspects have been identified to be major aspects of the evolution of industrial clusters and innovative milieux (cf. Brenner 2000).

The paper proceeds as follows. In Section two the basic model is developed. Section three focuses on a case with five spatially independent regions. The dynamics found in simulations are analysed with respect to the concentration of industries within one or several regions and with respect to the spatial relation and spillovers between industries. In Section four the model is expanded to situation with 49 regions that are located on a $7 \times 7$ grid and where spillovers between and spin-offs in neighbouring regions occur. The impact of these two aspects on the spatial distribution of two industries are studied and discussed. Section five concludes. 


\section{Basic model}

\subsection{Dynamics of Firms}

The basic elements of the model are firms. The number of firms is endogenously given since we allow for the entry and exit of firms. The state of each firm is characterised by several variables which all change endogenously. Furthermore, several parameters are defined that determine the behaviour of firms and there surrounding. These parameter are given exogenous and their influence on the spatial distribution of industrial activity is studied below.

The variables that define the state of a firm $n(\in \mathcal{N}(t))$ at time $t(t \in$ $\{0,1,2, \ldots\})$ are its capital $K_{n}(t)$, its labour force $L_{n}(t)$, its technology $T_{n}(t)$, and its liquidity $B_{n}(t)$. Furthermore, each firm is assigned to a region $q_{n}(\in \mathcal{Q})$ and an industry $i_{n}(\in \mathcal{I})$ which cannot be changed during the life of a firm.

The production function of a firm is assumed to depend on its attributes $K_{n}(t)$, $L_{n}(t)$, and $T_{n}(t)$. Besides these usual determinants technological spillovers from other firms are assumed to influence the production capacity. These spillovers are the only kind of positive local external economies that are considered here. All other aspects of agglomeration economies that are discussed in the literature are excluded in this approach in order to restrict the model to a few local mechanisms. Thus, the model developed here is adequate only for analysing the evolution of technological clusters where firms profit from technological spillovers from other firms located in the same or neighbouring regions. Industrial clusters or districts which are based on vertical and horizontal contacts and co-operations are not adequately represented by this approach. Furthermore, this approach does not deal with the labour market in detail. It concentrates on the evolution of a local system that has been called technological cluster elsewhere (cf. Brenner 2000).

Spillovers are bound with respect to location and industry. Therefore, we define a value $S_{q, i}(t)$ which denotes the spillovers that a firm belonging to industry $i$ at location $q$ can profit from. The value of $S_{q, i}(t)$ is discussed below in detail. The spillovers and the technological state $T_{n}(t)$ of a firm determine the steepness of the production function. With respect to the production factors $K_{n}(t)$ and $L_{n}(t)$ a Cobb-Douglas production function is assumed here, so that the output $Y_{n}(t)$ of firm $n$ of industry $i$ in region $q$ is given by

$$
Y_{n}(t)=\left[T_{n}(t)^{\gamma_{i}} \cdot S_{q, i}(t)\right] \cdot K_{n}(t)^{\alpha_{i}} \cdot L_{n}(t)^{\beta_{i}} .
$$

The partial output elasticities $\alpha_{i}$ and $\beta_{i}$ are parameters that are identical for all firms of the same industry. They may, however, differ between industries. The same holds for $\gamma_{i}$.

It is assumed here that firms are not able to influence their technology $T_{n}(t)$ and the amount of spillovers $S_{q, i}(t)$. This means that the possibility to vary the amount of R\&D-expenditures is neglected. All firms of one industry are assumed to spend the same amount on $R \& D$ and, therefore, have the same probability to improve their technology. Whether a firm $n$ is able to improve its technology at time $t$ is a random event. With a probability $p_{I, i}$ a firm of industry $i$ is assumed to innovate at time $t$, which improves its technology by 0.01 . Thus, each improvement is an incremental step. The impact of this incremental step, 
however, is assumed to decrease with the value of the technology $T_{n}(t)$ that is already reached. Therefore, the value $T_{n}(t)^{\gamma_{i}}$ enters the production function with $0<\gamma_{i}<1$.

The amount of capital $K_{n}(t)$ and labour $L_{n}(t)$ that are used in the production process are chosen by the firm. To this end, the optimal factor inputs are calculated at each time for a given demand. The firms are assumed not to be able to predict the demand they face in the next period. Therefore, they take the average of the demands at the present and the previous time as an approximation for the demand they should expect in the next period, which is denoted by $\hat{D}_{n}(t)$. Similarly, they assume wages, spillovers and their technology to remain constant. Thus, the optimal capital and labour inputs are

$$
K_{n, o p t}(t)=\left(\frac{\hat{D}_{n}(t) \cdot w_{q}(t-1)^{\beta_{i}} \cdot \alpha_{i}^{\beta_{i}}}{\beta_{i}^{\beta_{i}} \cdot r^{\beta_{i}} \cdot T_{n}(t-1)^{\gamma_{i}} \cdot S_{q, i}(t-1)}\right)^{\frac{1}{\alpha_{i}+\beta_{i}}}
$$

and

$$
L_{n, o p t}(t)=\left(\frac{\hat{D}_{n}(t) \cdot r^{\alpha_{i}} \cdot \beta_{i}^{\alpha_{i}}}{\alpha_{i}^{\alpha_{i}} \cdot w_{q}(t-1)^{\alpha_{i}} \cdot T_{n}(t-1)^{\gamma_{i}} \cdot S_{q, i}(t-1)}\right)^{\frac{1}{\alpha_{i}+\beta_{i}}}
$$

where $w_{q}(t)$ denotes the wage rate in region $q$ at time $t$ and $r$ is the interest rate on the capital market.

However, firms do not always change their capital and labour input to the optimal value within one period. The expansion of capital is costly and takes time and capital investment is in general irreversible, while labour has to be hired and in some cases trained. Thus, it is assumed that capital increases by maximally $5 \%$ and decreases by maximally $10 \%$ each period. Furthermore, investment also depends on the liquidity $B_{n}(t)$ of a firm and is assumed to be determined in the following way. First, set $K_{n, \downarrow}(t)=0.9 \cdot K_{n}(t-1)$ and $K_{n, \uparrow}(t)=1.05 \cdot K_{n}(t-1)$. Then,

$$
K_{n}(t)-K_{n}(t-1)=\left\{\begin{array}{lcc}
-0.1 \cdot K_{n}(t-1) & \text { if } & K_{n, o p t}(t)<K_{n, \downarrow}(t) \\
\frac{K_{n, o p t}(t)-K_{n, \downarrow}(t)}{1+\exp \left[\frac{B_{n}(t)}{K_{n, o p t}(t)-K_{n, \downarrow}(t)}\right]} & \text { if } & K_{n, \downarrow}(t)<K_{n, o p t}(t)<K_{n, \uparrow}(t) \\
\frac{K_{n, \uparrow}(t)-K_{n, \downarrow}(t)}{1+\exp \left[\frac{B_{n}(t)}{K_{n, \uparrow}(t)-K_{n, \downarrow}(t)}\right]} & \text { if } & K_{n, o p t}(t)>K_{n, \uparrow}(t)
\end{array}\right.
$$

This equation is arbitrarily chosen to reflect the fact that the higher the liquidity of a firm, the more money it will invest up to the level which is optimal and possible.

The amount of labour employed is assumed to be chosen such that the marginal factor productivity is the same for capital and labour. Again changes are restricted to a maximum of $50 \%$ of the previous labour input. However, since the labour input is related to the capital input, the dynamics of capital and labour inputs are in general limited by the restrictions on the changes of capital. $L_{n}(t)$ is always a natural number representing the number of employees.

The liquidity of firms is updated each period by subtracting the money invested $\left(K_{n}(t)-K_{n}(t-1)\right)$, the costs of capital $\left(r \cdot K_{n}(t)\right)$, the labour costs $\left(w_{q}(t) \cdot L_{n}(t)\right)$, 
and the fixed costs $F_{i}$ and adding the returns from selling the good on the market $\left(P_{n}(t) \cdot D_{n, s}(t)\right)$. The fixed costs are an industry-specific parameter. $P_{n}(t)$ and $D_{n, s}(t)$ are described in detail below.

Firms are assumed to be price setters. As outlined above firms adapt their production to the demands they face. The price is set according to a mixture of markup-pricing and an orientation towards the market price. To use mark-up pricing, the costs of production have to be calculated. The average costs are

$$
c_{n}(t)=\frac{F_{i}+r \cdot K_{n}(t)+w_{q}(t) \cdot L_{n}(t)}{Y_{n}(t)} .
$$

The price $P_{n}(t)$ charged by firm $n$ at time $t$ is assumed to be given by

$$
P_{n}(t)=\mu_{i} \cdot\left(1+m_{i}\right) \cdot c_{n}(t)+\left(1-\mu_{i}\right) \cdot \bar{P}(t-1)
$$

where $\mu_{i}$ and $m_{i}$ are industry-specific parameters and $\bar{P}(t)$ is the average price for which the good is traded on the market, which is called the market price in this approach. $m_{i}$ is the mark-up used in industry $i$, while $\mu_{i}$ determines how much firms stick to the price resulting from the mark-up rule instead of orienting on the market price. The calculation of the market price is given in Equation (2.10).

\subsection{ENTRY AND EXIT OF FIRMS}

Firms are removed either if they employ only one worker (this threshold is chosen for convenience) or if their liquidity falls below a certain trash-hold $B_{\min }$.

New firms occur due to two processes: random entry and spin-offs. First, with a constant probability $p_{F, q}$ a firm enters at any time $t$ for any industry (this probability may vary between regions). Such a firm starts with an initial set of variables given by $K_{\text {init }}, L_{\text {init }}$, and $B_{\text {init }}$. The initial value of $T_{n}$ is determined by calculating the average value of $T_{\tilde{n}}(t)$ for all firms $\tilde{n}$ that belong to the same industry. To this average value an amount of either $0,0.01$ or 0.02 is added with equal probability. This can be interpreted as follows. From time to time someone has, starting from the average technological standard, an innovative idea and founds a new firm to exploit this idea.

Second, within a region with a probability, depending on the number of firms that belong to a certain industry and are located in this region, a spin-off firm is founded. The probability for such a spin-off is given by

$$
\frac{N_{i, q} \cdot p_{S, q}}{N_{i, q} \cdot p_{S, q}-p_{S, q}+1}
$$

where $N_{i, q}$ denotes the number of firms in region $q$ that belong to industry $i$ and $p_{S, q}$ is a parameter, dependent on the region. A spin-off firms starts with the same initial variables as defined above, namely $K_{\text {init }}, L_{\text {init }}$, and $B_{\text {init }}$, except for the technology. To determine the technology of a spin-off firm, one of the firms of the same industry in the region is chosen randomly. The spin-off firm is assumed to be a spin-off of this firm and, therefore, imitates the technology of this firm. Again either 0, 0.01, or 0.02 is added with equal probability, representing the fact that the spin-off firm might innovate right at the beginning. 


\subsection{TEChNOLOGICAL SPILlOVERS}

In empirical studies it has been repeatedly shown that firms profit a lot from spillovers from other firms. These spillovers have been shown to be to some extend a localised phenomenon (cf. Jaffe, Trajtenberg \& Henderson 1992 and Audretsch 1998). Therefore, we consider local spillovers between firms in this approach. In a first approach in Section 3 spillovers are assumed to occur only within regions. In Section 4 we will also allow for spillovers between neighbouring regions. With respect to industries, inter-industrial spillovers are explicitly considered. The amount of spillovers within and between industries is denoted in the form of a spillover matrix $\left(s_{i j}\right)_{i, j \in \mathcal{I}}$. The total spillover that a firm of industry $i$ in region $q$ profits from is defined by

$$
S_{q, i}=\left[\sum_{\substack{n \in \mathcal{N}(t) \\ q_{n}=q}} s_{i i_{n}} \cdot T_{n}(t)\right]^{\sigma_{i}} .
$$

The influence of this spillover on the production function of each firm is given above in Equation (2.1).

\subsection{LABOUR MARKET}

Labour markets are assumed to be local in this approach. This means that we exclude any kind of movement of the labour force. Thus, a firm can only employ people from the region where itself is located in. Wages result to be variables of the regions. A differentiation of the labour market with respect to industries is not considered. The wage rate $w_{q}(t)$ within a region is assumed to be given by

$$
w_{q}(t)=w_{q, 0} \cdot\left[\sum_{\substack{n \in \mathcal{N}(t) \\ q_{n}=q}} L_{n}(t)+L_{q, \text { other }}\right]
$$

where $w_{q, 0}$ is a parameter determining the basic wage level in region $q$ and $L_{q, \text { other }}$ is a parameter denoting the labour demand of all other industries in region $q$ that are not explicitly considered in the model. The labour demand of all other industries is assumed to remain constant. This parameter determines whether wages react more or less strongly to changes in the labour demand of the explicitly modelled firms.

\subsection{MARKET AND FIRM-SPECIFIC DEMAND}

All firms of one industry are assumed to produce the same kind of good. Thus, they supply the same market and compete on this market. However, it is assumed that the goods are not identical, so that they are substitutable but not all customers will choose automatically the most inexpensive good.

Hence, to calculate the demand for each firm $n$, two steps are necessary. First, the overall demand has to be determined. Then, this demand has to be distributed between the firms of the respective industry. Demand is assumed to be global, so that no distinction with respect to the locality of firms is necessary. The overall demand for one kind of good is assumed to depend on the average 
price of the good, which was above called the market price. The average price for the good of industry $i$ is given by

$$
\bar{P}_{i}(t)=\sum_{\substack{n \in \mathcal{N}(t) \\ i_{n}=i}}\left[D_{n, s}(t-1) \cdot P_{n}(t)\right]
$$

where for each firm the number of sold goods $D_{n, s}(t-1)$ in the last period is used to avoid a circular definition of demands. The market demand $\bar{D}_{i}(t)$ is assumed to be given by

$$
\bar{D}_{i}(t)=\frac{\bar{D}_{i, 0}}{\bar{P}_{i}(t)}
$$

where $D_{i, 0}$ is an industry-specific parameter.

The market demand $\bar{D}_{i}(t)$ is distributed between the firms of industry $i$ according to their prices. The higher the price of a firm the smaller the demand for the good produced by this firm will be. However, since we assume that goods are not identical, firms with higher prices will still sell some pieces of the good, at least if their prices are not too high. To model these characteristics, a market share factor $M_{n}(t)$ is defined for each firm $n$ by

$$
M_{n}(t)=\left\{\begin{array}{lll}
\frac{\phi_{i_{n}} \cdot \bar{P}_{i_{n}}(t)}{P_{n}(t)}-1 & \text { if } & \frac{P_{n}(t)}{P_{i_{n}}(t)}<\phi_{i_{n}} \\
0 & \text { if } & \frac{P_{n}(t)}{P_{i_{n}}(t)}>\phi_{i_{n}}
\end{array}\right.
$$

where $\phi_{i_{n}}$ is a industry-specific parameter, which determines how much firms are able to charge for the good without being neglected by the customers. All firms with a price above $\phi_{i} \cdot \bar{P}_{i_{n}}(t)$ do not sell any piece of the good. Below this value the demand for a firm's good decreases with its price. The demand for the good of firm $n$ is calculated according to

$$
D_{n}(t)=\frac{M_{n}(t) \cdot \bar{D}_{i_{n}}(t)}{\sum_{\substack{\tilde{n} \in \mathcal{N}(t) \\ i_{\tilde{n}}=i_{n}}} M_{\tilde{n}}(t)} .
$$

This $D_{n}(t)$ equals the number of goods $D_{n, s}(t)$ that are sold by the firm if the firm is able to produce enough goods. If it is not able to do so, the number of goods sold equals the possible output, meaning $D_{n, s}(t)=Y(t)$.

\section{Analysis of simulations with independent regions}

Before we analyse a model with a spatial distribution of regions and spillovers between neighbouring regions, the above model will be simulated and analysed for five independent regions and two industries. Through this the influence of all parameters is studied in detail. The analysis of the more complex spatial setting in the next section can then be restricted to those parameters that influence the spatial distribution of industrial activity.

The study of five independent regions proceeds in four steps. Firstly, the initial dynamics of the simulations are discussed. Secondly, a sensitivity analysis is conducted for all parameters. Thirdly, the parameters that cause firms to agglomerate in one or a few regions are analysed and discussed. Finally, the implications of a successive introduction of industries are analysed. 


\subsection{INITIAL DYNAMICS}

In the following sensitivity analysis we study the impact of all parameters on the final distribution of firms and employment. However, before such an analysis is conducted we have to study what 'final' means and how the dynamics in the simulations look like. To this end the initial dynamics for all parameter sets that have been used, are studied.

The surprising result is that convergence occurs for all parameter sets. Many simulations have been run for large numbers of periods (up to 10000), but in all the distribution of firms and employment had converged after 2000 periods, except some small fluctuations. In most case convergence even took place before the first 500 periods had been finished. Only a few simulation runs have offered some surprising change in the spatial structure in a later period (see for example Figure 1). Thus, after an initial phase the spatial distribution of economic activity remains constant if the exogenous circumstances do not change.

\section{industry 1}

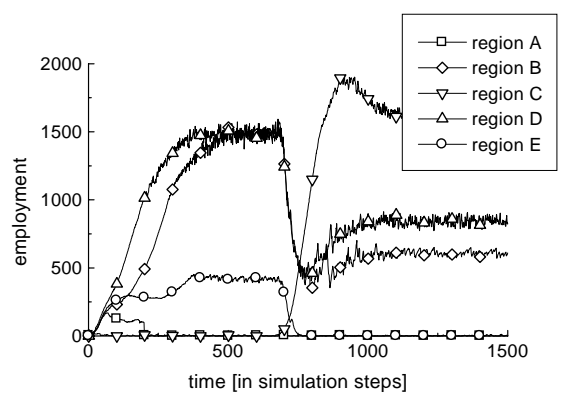

\section{industry 2}

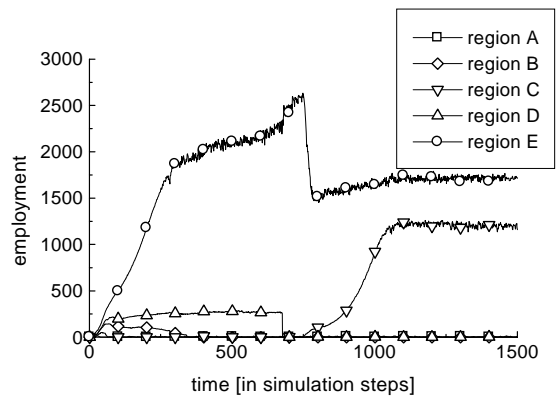

Figure 1: Exemplary dynamics for the standard parameter set, except $F_{i}=0 \forall i=1,2$.

Another surprising result of the simulations is that re-running a simulation with the same parameters often leads to a different spatial distribution of firms and employment. The processes simulated show a clear path-dependence. Of course, some path-dependency can be expected in all cases where firms and employment concentrate in one or a few regions. Since all regions are assumed to be identical, the concentration should occur in different regions for different runs, dependent on stochastic events, like the founding of new firms and technological advances.

However, this is not the only kind of path-dependency that can be found in the simulations. The spatial structure also varies for many parameter sets. There are, for example, parameter sets where in one run the firms concentrate in one region while in the next run they are distributed over four of the five regions. Similarly, there are parameter sets where in one run the firms of both industries agglomerate in the same region while in the next run the firms of one industry 
are distributed over three regions and the firms of the other industry agglomerate in another region. There are plenty of such results. There seems to be no stable distribution for many of the parameter sets. Thus, path-dependency does not only occur with respect to the regions where firms agglomerate, but also with respect to the number of regions that contain an agglomeration and the spatial relation between industries. This path-dependence has important implications for the dynamics of local systems which will be discussed in more detail at the end of this section.

\subsection{Sensitivity ANALYSis For ALL PARAMETERS}

We will neglect the initial dynamics during the sensitivity analysis. Instead, we study for each parameter whether the parameter has an influence on the final distribution of firms and employment. To this end, the final state has to be characterised by some well-defined aspects. Four aspects are used here: 1) the number of regions that contain a significant number of employment of an industry, denoted by $\left.Q_{s}, 2\right)$ the share of those regions that contain also a significant number of employment of the other industry, denoted by $Q_{d}, 3$ ) the total number of employment, denoted by $L$ and 4 ) the total number of firms, denoted by $N$.

The aim of the sensitivity analysis is to identify for each parameter the aspects that are influenced by the parameter. Therefore, each parameter is varied in both directions and a statistical analysis of the resulting changes of $Q_{s}, Q_{d}, L$, and $N$ is conducted. Before this can be done, a standard parameter set has to be defined. We have chosen this parameter set such that it leads to some intermediate results according to the aspects above, meaning that there is neither a complete concentration on one region nor an equal distribution of the employment over all region and that there is neither a strict separation of the two industries nor a strict coexistence. This standard parameter set is given by $\alpha_{i}=0.5, \beta_{i}=0.5$, $\gamma_{i}=0.4, \sigma_{i}=0.4, p_{I, i}=0.1, F_{i}=1, r=0.1, m_{i}=0.05, \mu_{i}=0.7, B_{\min }=-10$, $p_{F, q}=0.1, p_{S, q}=0.02, K_{\text {init }}=5, L_{\text {init }}=5, B_{\text {init }}=10, s_{i i}=\frac{1}{3}, s_{i j}=\frac{1}{9} \forall i \neq j$, $w_{q, 0}=0.0001, L_{q, o t h e r}=1000, \bar{D}_{i, 0}=2000$, and $\phi_{i}=1.5$. Furthermore, the simulations are started in the standard case with no firms existing and an initial value of technology of $T_{\text {init }}=1$. The spillovers for each region and industry are set to $S_{q, i}=0.5$ if no corresponding firm exists. The results of the sensitivity analysis are given in Table 1.

Table 1 shows that only a few parameters have no influence on the final state of the simulations. Most of the parameters influence all four aspects. However, this paper intends to study the spatial distribution of industries to learn more about the evolution of industrial clusters. Thus, the analysis focuses on the industrial, geographical concentration and the spatial relation between the two industries. These aspects are discussed below in more detail. The impacts on the total number of firms and employment are given in Table 1 only for completion. The aim of the sensitivity analysis is to identify those parameters that influence the spatial distribution of industries. 


\begin{tabular}{|c|c|c|c|c|}
\hline & $Q_{d}$ & $Q_{s}$ & $L$ & $N$ \\
\hline$\alpha_{i}\left(K_{i n i t}=10 \cdot \alpha_{i}\right)$ & 0 & - & - & - \\
\hline$\beta_{i}\left(K_{i n i t}=\frac{2.5}{\beta_{i}}\right)$ & - & $\mathrm{U}$ & + & - \\
\hline$\gamma_{i}$ & 0 & 0 & 0 & 0 \\
\hline$\sigma_{i}$ & $\mathrm{U}$ & - & - & - \\
\hline$p_{I, i}$ & + & 0 & - & 0 \\
\hline$F_{i}$ & - & $\mathrm{U}$ & 0 & - \\
\hline$r\left(K_{i n i t}=\frac{1}{2 r}\right)$ & 0 & - & - & + \\
\hline$m_{i}$ & 0 & + & + & + \\
\hline$\mu_{i}$ & + & + & + & - \\
\hline$B_{\min }$ & 0 & 0 & 0 & 0 \\
\hline$p_{F, q}$ & + & + & 0 & + \\
\hline$p_{S, q}$ & 0 & + & 0 & + \\
\hline$B_{\text {init }}$ & 0 & $\mathrm{U}$ & + & + \\
\hline$s_{i i}$ & - & - & + & - \\
\hline$s_{i j}$ & + & + & - & 0 \\
\hline$L_{q, \text { other }}\left(w_{q, 0}=\frac{0.1}{L_{q, \text { other }}}\right)$ & + & - & + & 0 \\
\hline $\bar{D}_{i, 0}$ & - & + & + & + \\
\hline$\phi_{i}$ & 0 & + & 0 & + \\
\hline
\end{tabular}

Table 1: Results of the sensitivity analysis. To obtain these results, for any parameter two values well above and below the standard value have been used and the differences of the resulting values $Q_{d}, Q_{s}, L$, and $N$ studied. ' + ' denotes a positive influence, '-' a negative influence, ' $U$ ' denotes an influence that leads to an increase for low and for high values of the parameter, and ' 0 ' denotes no significant influence (the results are all significant at $0.001)$.

\subsection{Geographic industrial CONCENTRATION}

The aim of this approach is to develop a better understanding for the evolution of industrial clusters. Therefore, the parameters that influence the degree of concentration deserve a comprehensive treatment. Above it has been reported that quite a few parameters have an impact on the number of regions that are populated with a significant number of firms in the long run. These are $\alpha_{i}, \beta_{i}$, $\sigma_{i}, F_{i}, r, m_{i}, \mu_{i}, p_{F, q}, p_{S, q}, B_{\text {init }}, s_{i i}, s_{i j}, L_{q, o t h e r}, \bar{D}_{i, 0}$ and $\phi_{i}$. 
However, the influence of these parameters on the geographic industrial concentration is of different strength. To find those parameters that are most relevant, we use an experimental design and analyse the results statistically (cf. Witt 1986 where a similar approach is taken on a related topic and Winer 1971 the method is discussed generally). The dependent variable that is to be explained is the number of regions with a significant number of employment of an industry $D_{s}$. The independent variables are all parameters that have been identified to have an influence on $D_{s}$. For each independent variable we choose two or three (in the case of a U-shaped dependence) values such that the corresponding values of $D_{s}$ differ from each other by the same amount (approximately 0.5) for all parameters. In the case of $s_{i i}$ and $s_{i j}$ such a difference cannot be obtained. A difference of around 0.3 was obtained for these parameters. The values for all parameters that are included are given in Table 2.

A simulation is run for each combination of these values, meaning that in total 110592 simulations are run. For each run $D_{s}$ is recorded. It is assumed that $D_{s}$ can be explained as a linear combination of the values of $\alpha_{i}, \beta_{i}, \sigma_{i}, F_{i}, r, m_{i}, \mu_{i}$, $p_{F, q}, p_{S, q}, B_{\text {init }}, s_{i i}, s_{i j}, L_{q, o t h e r}, \bar{D}_{i, 0}$, and $\phi_{i}$. Therefore, a multiple regression is conducted with the results given in Table 2. The regression factors show the amount of changes in $D_{s}$ that each of the parameters causes ${ }^{\dagger}$. This first of all reveals that four parameters, namely $F_{i}, r, B_{\text {init }}$ and $\bar{D}_{i, 0}$ loose their influence if all parameter are varied.

All other parameters have a significant influence. The change they cause depends on the amount by which they are changed themselves. Since we have no information about the range of most of the parameters in reality, it is not possible to deduce from the regression factors the relevance of the parameters for the evolution of industrial clusters in the real world. The regression parameters only give us some hints about the reaction of the agglomeration forces on changes of the respective parameters.

To gether more information about the relevance of each of the parameters the regression is conducted for each parameter separately. One may claim that a parameter dominates another if the changes of the depended variable are mainly explained by one parameter, although both parameters are changed such that according to the sensitivity analysis both should lead to the same variation of the dependend variable. If no parameter dominates any other in the above sense, all parameters should have the same explanatory value for the variations of $D_{s}$. We use the $R^{2}$-value of the separate regression as a measure of the explanatory power of each parameter. This value is given in the last row of Table 2. The table shows that the parameters contribute very differently to the explanation of the geographic industrial concentration.

The parameter that contributes most is the number of employees $L_{q, \text { other }}$ in other industries within a region. This fact that is not surprising. If wages react strongly on the change in the demand for labour, firms tend to distribute equally between regions. If, instead, wages are quite inelastic with respect to changes in the demand for labour, the tendency towards spatial concentration is supported. As modelled here, the reaction of wages depends on the relation between the

$\dagger$ Of course, this approach does only result in some local and linear knowledge about the dependence of $D_{s}$ on the parameters. 


\begin{tabular}{|c|c|c|c|c|c|c|}
\hline & $\begin{array}{l}\text { low } \\
\text { value }\end{array}$ & $\begin{array}{l}\text { middle } \\
\text { value }\end{array}$ & $\begin{array}{l}\text { high } \\
\text { value }\end{array}$ & $\begin{array}{l}\text { regression } \\
\text { factor }\end{array}$ & $\begin{array}{l}\text { significance } \\
\text { level }\end{array}$ & $\begin{array}{c}R^{2} \text { for } \\
\text { separate regression }\end{array}$ \\
\hline$\alpha_{i}$ & 0.45 & & 0.55 & -2.600 & 0.0001 & 0.0079 \\
\hline$\beta_{i}$ & 0.47 & 0.49 & 0.54 & 1.2855 & 0.01 & 0.0005 \\
\hline$\sigma_{i}$ & 0.36 & & 0.44 & -4.322 & 0.0001 & 0.0139 \\
\hline$F_{i}$ & 0.83 & 0.9 & 1.75 & 0.0266 & 0.1 & 0.0001 \\
\hline$r$ & 0.097 & & 0.103 & -0.1886 & - & 0 \\
\hline$m_{i}$ & 0.035 & & 0.065 & 11.8885 & 0.001 & 0.0148 \\
\hline$\mu_{i}$ & 0.6 & & 0.8 & -0.2207 & 0.1 & 0.0002 \\
\hline$p_{F, q}$ & 0.05 & & 0.3 & 3.1534 & 0.0001 & 0.0724 \\
\hline$p_{S, q}$ & 0.005 & & 0.7 & 0.9928 & 0.0001 & 0.0555 \\
\hline$B_{\text {init }}$ & 2 & 8 & 25 & 0.0035 & 0.1 & 0.0003 \\
\hline$s_{i i}$ & $\frac{1}{18}$ & & 1 & -0.5902 & 0.0001 & 0.0362 \\
\hline$s_{i j}$ & $\frac{1}{36}$ & & $\frac{1}{3}$ & 1.1990 & 0.0001 & 0.0156 \\
\hline$L_{q, \text { other }}$ & 400 & & 3000 & -0.0006 & 0.0001 & 0.2819 \\
\hline $\bar{D}_{i, 0}$ & 200 & & 8000 & 0.000002 & - & 0 \\
\hline$\phi_{i}$ & 1.3 & & 2 & 0.5823 & 0.0001 & 0.0194 \\
\hline
\end{tabular}

Table 2: Results of the multiple and the separate regressions.

number of employees within an industry and the total labour force available. Industries with an high total employment have a much stronger effect on local wages if they agglomerate than industries with a low total employment. Thus, huge industries should be expected to concentrate less.

The three parameters that come next according to their explanatory power are the parameters $p_{F, q}, p_{S, q}$ and $s_{i i}$. The parameters $p_{F, q}$ and $p_{S, q}$ determine the frequency with which start-ups occur. A closer view on the simulations shows that at the beginning start-ups are very likely to survive, while once a number of large firms have established that satisfy the market, entering firms exit after a short period of time. Thus, the final distribution is strongly influenced by the events at the beginning. A higher frequency of entries in all regions leads to a more equal distribution between regions, which manifests itself with time. Therefore, $p_{F, q}$ and $p_{S, q}$ have a positive influence on the number of regions in which an industry can be found. Thus, industries with high rates of entries at the beginning should be expected to be less concentrated.

$\sigma_{i}$ determines the amount of spillovers within a region and industry. Spillovers 
are repeatedly supposed to be one of the most important reasons for economic agglomerations in the literature. This study supports that view. The more spillovers occur, the more economic activity will concentrate. Thus, industries where firms profit very much from spillovers should be spatially more concentrated than industries where firms profit less from spillovers.

\subsection{Spatial Relation Between the industries}

To obtain a better understanding for the spatial relation between industries, a similar approach is taken as the one above. The parameters that have been found to influence $Q_{d}$ in the sensitivity analysis are $\beta_{i}, \sigma_{i}, p_{I, i}, F_{i}, \mu_{i}, p_{F, q}, s_{i i}$, $s_{i j}, L_{q, o t h e r}$ and $\bar{D}_{i, 0}$. Again for each of these parameters two or three values have been chosen such that $Q_{d}$ varies by an amount of approximately 0.3. In the cases of $F_{i}$ and $\bar{D}_{i, 0}$ only variations of around 0.15 and 0.25 , respectively, have been possible. For each parameter combination a simulation has been run, implying a total number of 1536 simulation runs. A regression analysis has been conducted in the same way as the one above and the results are given in Table 3 .

\begin{tabular}{ccccccc}
\hline & $\begin{array}{c}\text { low } \\
\text { value }\end{array}$ & $\begin{array}{c}\text { middle } \\
\text { value }\end{array}$ & $\begin{array}{c}\text { high } \\
\text { value }\end{array}$ & $\begin{array}{c}\text { regression } \\
\text { factor }\end{array}$ & $\begin{array}{c}\text { significance } \\
\text { level }\end{array}$ & $\begin{array}{c}R^{2} \text { for } \\
\text { separate regression }\end{array}$ \\
\hline$\beta_{i}$ & 0.44 & & 0.56 & -0.2718 & 0.0001 & 0.0060 \\
\hline$\sigma_{i}$ & 0.2 & 0.4 & 0.9 & 0.0584 & 0.0001 & 0.0043 \\
\hline$p_{I, i}$ & 0.01 & 0.4 & 0.0023 & - & 0 \\
\hline$F_{i}$ & 0.7 & 1.7 & 0.0054 & 0.1 & 0.0002 \\
\hline$\mu_{i}$ & 0.5 & 0.86 & 0.2928 & 0.0001 & 0.0274 \\
\hline$p_{F, q}$ & 0.05 & 0.3 & 0.28 & 0.0001 & 0.3096 \\
\hline$s_{i i}$ & $\frac{1}{9}$ & $\frac{2}{5}$ & -0.8139 & 0.0001 & 0.0205 \\
\hline$s_{i j}$ & $\frac{1}{12}$ & $\frac{1}{8}$ & 1.4508 & 0.0001 & 0.0011 \\
\hline$L_{q, \text { other }}$ & 100 & 3000 & -0.000005 & 0.001 & 0.0001 \\
\hline $\bar{D}_{i, 0}$ & 200 & 20000 & -0.0000002 & 0.1 & \\
\hline
\end{tabular}

Table 3: Results of the multiple and the separate regressions.

The regressions shows a clear domination of four parameters, namely $s_{i i}, \mu_{i}$, $p_{F, q}$ and $s_{i j}$. The latter one of these parameters does not need any further discussion. It seems to be natural that an increase of spillovers between industries leads to a higher likelihood of the industries to locate in the same regions. It is rather surprising that the other three parameters seem to have a stronger influence. 
The domination of $s_{i i}$ can be explained as follows. An increase of $s_{i i}$ causes a distribution of each industry over a large number of regions. Since the number of regions has been restricted to five here, this means that the two industries are not able any more to locate in different regions. This aspect seems to be less relevant in reality where much more than five locations exist.

The parameters $\mu_{i}$ and $p_{F, q}$ require are closer look at the dynamics of the simulations. $p_{F, q}$, as has been discussed above, leads to a more equal distribution of the industries between the regions, and therefore to a lower concentration of the each industry and more local coincidences between the industries. A large value of $\mu_{i}$ causes start-ups, which generally produce less efficient than existing firms due the economies of scale, to charge prices much higher than the market price. This decreases their likelihood to enter the market quickly after an initial phase. As a consequence, the situation becomes quite fixed after a shorter period of time. This gives the concentration forces less time to operate and the concentration of industries decreases. Hence, according to the argument above, the probability of both industries to be located in the same region increases. Again both mechanisms require a restricted number of regions to work properly. Thus, the only parameter that can be expected to matter also in reality is $s_{i j}$.

\subsection{Dynamics For the successive introduction of Industries}

Above it has been found that the spatial distribution of industries shows a strong path-dependency. This implies that one should expect the resulting spatial distribution to depend strongly on the temporal order of exogenous events. Above all simulations have been run with both industries introduced right at the beginning of the simulations. An alternative procedure would be to introduce the industries one after the other. Due to the path-dependency it should be expected that the results differ significantly between the situation where both industries are introduced at the same time and the situation where one industry is introduced later.

Therefore, we study such dynamics for five parameter sets. The five parameter sets are chosen such that they represent different types of spatial distributions, in the case of a simultaneous introduction of the industries. This means that we consider a parameter set where both industries always concentrate in one region (standart parameter set except $L_{q, \text { other }}=10000$ ), one where all regions contain a significant number of firms of both industries (standard parameter set except $s_{12}=s_{21}=\frac{1}{3}$ and $\left.L_{q, \text { other }}=100\right)$, one where both industries concentrate in different regions (standard parameter set except $s_{12}=s_{21}=\frac{1}{100}$ and $L_{q, \text { other }}=$ 10000), one where all regions are populated by only one industry (standard parameter set except $\left.L_{q, \text { other }}=100\right)$, and one where the results of the simulations vary and are somewhere between the other four situations (standard parameter set except $s_{12}=s_{21}=\frac{2}{9}$ ). With these parameter sets simulations were run where the first industry is introduced right at the beginning of the simulation and the second one is added after 1500 simulation step, after the spatial distribution for the first industry has converged.

In the situations where both industries are concentrated in one region either in the same or in two different ones in the original setting, the successive introduction of the industries does not change the results. 
industry 1

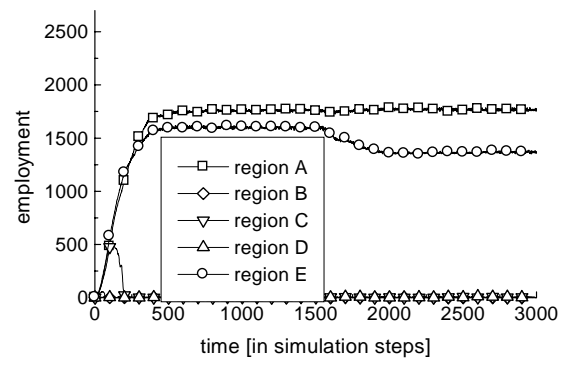

industry 2

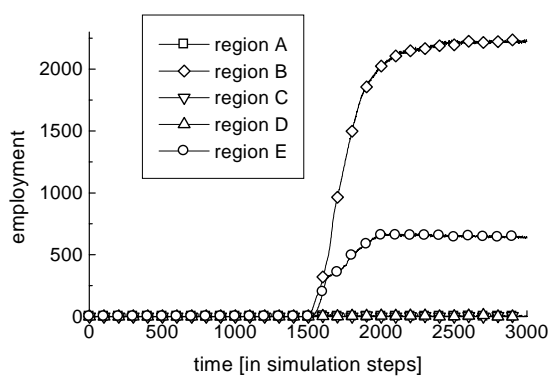

Figure 2: Exemplary dynamics for a successive introduction of the two industries with the standard parameter set, except $s_{12}=s_{21}=\frac{2}{9}$.

In the intermediate situation again the structure of the final distribution of firms varies a lot. However, it cannot be distinguished from the results of the former simulations where both industries have been introduced at the same time. Nevertheless, these simulations show how the introduction of the second industry affects the spatial distribution of the first industry. If the second industry locates in a region that contains already an agglomeration of the first industry it reduces the labour demand of the first industry's firms due to rising wages in the region (see Figure 2). Thus, the location of a new industry in a region might have a negative impact on the industry that is already located there. However, the opposite result might also occur. The location of the new industry in a so far 'empty' (industries that are not considered in the model might, of course, be located there) region might trigger the founding of firms belonging to the first industry. This might even lead to a situation where this region becomes dominant in both industries as can be seen in Figure 3. Summing up, in an intermediate situation a new industry might locate in a region where firms of the other industry have already agglomerated or might locate in other regions. Once the firms of the new industry agglomerate in one region, this has strong impacts for the spatial distribution of the other industry.

In the situation where above every region became populated by exactly one industry, the temporal order of the introduction of industries plays an important role for the final outcome. While only one industry is present, the firms of this industry become distributed over between three and five regions (given the standard parameter set except $L_{q, \text { other }}=100$ ). The second industry is then only able to get hold in one or two regions, whereby it sometimes displaces the first industry. As a consequence, the second industry is present in a smaller number of regions than the first one and is therefore more concentrated, although both industries are characterised by exactly the same parameters. This means that the concentration of an industry also depends on the time at which it is introduced. This effect is even stronger for a parameter set with $s_{12}=s_{21}=\frac{1}{100}$, $L_{q, \text { other }}=10$. In this case the simulations show that the firms of the first in- 
industry 1

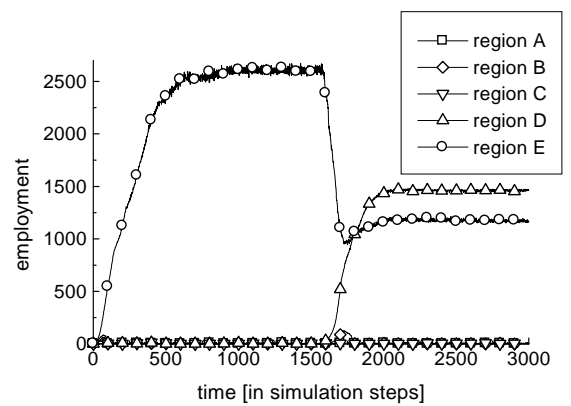

Figure 3: Exemplary dynamics for a successive introduction of the two industries with the standard parameter set, except $s_{12}=s_{21}=\frac{2}{9}$. industry 2

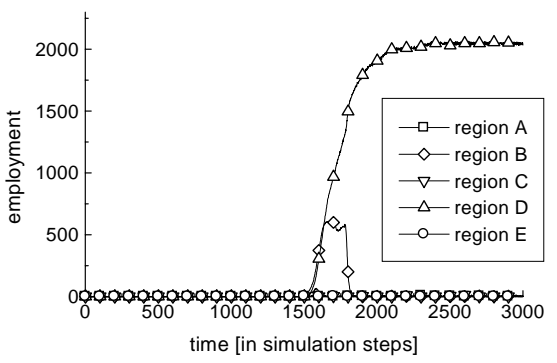

dustry are always spread over all regions. The circumstances are then such that the second industry is not able to get hold in any of the regions due to the high labour costs. However, whether the second industry concentrates more or less depends very much on the share of regions that are already occupied by the other industry. In reality, if industries concentrate spatially, each industry is in general agglomerated in only a few regions so that there should be plenty of regions left for new industries.

The most surprising result occurs in the situation where after a simultaneous introduction of both industries all regions contain a significant number of firms of both of them. If, instead, the industries are introduced successively, a separation of the industries can be observed. The dynamics are similar to those described in the last paragraph. The first industry is spread over between four and five regions when the second industry is introduced. The firms of the second industry then locate either in the region that is not populated by the first industry or randomly in one of the regions if all regions are populated by the first industry. In the latter case the firms of the first industry disappear in this region. Thus, the successive introduction of industries seems to make a spatial coincidence of industries less likely.

The study of a successive introduction of industries has confirmed the statement, that the history of external events matters for the spatial distribution of industrial activity. The spatial distribution of economic activity does not only depend on the actual circumstances (given by the parameter), but also on the values of these circumstances in the past. This does not only hold for the introduction of industries, as it has been shown here. Additional simulations, which will not be reported in detail here, have shown that for many of the parameters the results change if the values of these parameters in some early periods of time are changed, although the parameters remain the same at the end of the simulations and the system has enough time to converge. 


\section{Analysis of a spatial model}

In the last section the regional agglomeration of industries has been intensively studied under the assumption of technological spillovers that are restricted to spillovers within regions. The aspect that technological spillovers have a spatial dimension such that they also occur in a significant amount between locations that are near to each other (cf. Jaffe, Trajtenberg \& Henderson 1992) has been neglected. The impact of this aspect on the location of industries is studied in this section. All other aspects of the spatial distribution of industries, like its path-dependency, the determinants of industrial concentration and the dynamics of the related processes, which have been discussed in the last section, are neglected here. The analysis focuses on the impact of spillovers between neighbouring regions on the spatial distribution of the industries.

\subsection{Spatial MODEL}

There are two kinds of technological spillovers between neighbouring regions that are considered in this approach: spillovers that influence the production function of firms in the neighbouring regions and spin-offs that are founded in neighbouring regions.

To be able to include these to aspects in the above model, a spatial structure has to be defined first. We use a two-dimensional space with 49 quadratic regions of the same size. The space is defined to be circular so that the regions at the top of the space are neighbours to the regions at the bottom and the regions at the right of the space are neighbours to those on the left. Regions are called neighbour if they share a one-dimensional border. Hence, each region has four neighbours.

In the above model a spillover value $S_{q, i}(t)$ has been defined for each region and industry (see Equation (2.8)). To this value spillovers from neighbouring regions have now to be added. Thus, the spillover $\tilde{S}_{q, i}(t)$ has to be redefined according to

$$
S_{q, i}=\left[\sum_{\substack{n \in \mathcal{N}(t) \\ q_{n}=q}}\left[s_{i i_{n}} \cdot T_{n}(t)\right]+\sum_{\substack{n \in \mathcal{N}(t) \\ i_{n}=i \\ q_{n}=q \leftarrow, q_{\rightarrow}, q_{\uparrow}, q_{\downarrow}}}\left[\eta_{q} \cdot s_{i i} \cdot T_{n}(t)\right]\right]^{\sigma_{i}}
$$

where $\eta_{q}$ denotes the region-dependent share of technology that spills over to neighbouring regions and $q_{\leftarrow}, q_{\rightarrow}, q_{\uparrow}$, and $q_{\downarrow}$ denote the four regions that are neighbours to region $q$.

The model above contains two processes of entries of firms: a random entry and a spin-off process that is restricted to spin-offs within the region. In this section a third process is added: a spin-off process where the spin-off firm is founded in one of the neighbouring regions. The probability of the entry of such a firm is for each of the neighbouring regions given as one fourth of

$$
\frac{N_{i, q} \cdot p_{N, q}}{N_{i, q} \cdot p_{N, q}-p_{N, q}+1}
$$

where $p_{N, q}$ is a region-specific parameter denoting the likelihood of such spin-offs. 


\subsection{ANALYSIS OF INDUSTRIAL CONCENTRATION}

As mentioned above the analysis of the spatial model is restricted to a study of the impact of the two new processes on the spatial concentration of industries and the spatial relation between the industries. Since the elasticity of wages, determined by $L_{q, o t h e r}$, and the amount of spillovers between industries $s_{i j}$ have been found above to be especially important for the spatial relation between the industries, these parameters are also included in the following analysis. Thus, four independent variables are studied, namely $s_{n, i}, p_{N, i}, L_{q, \text { other }}$ (where $\left.w_{q, 0}=\frac{0.1}{L_{q, \text { other }}}\right)$, and $s_{i j}$. As dependent variables measures for the concentration of industries and the spatial relation between industries have to be found.

For both aspects the average distance between employees can be used. To this end, we first have to define the distance between two regions. Due to the importance of neighbourhood in this approach, it seems to be adequate to define the distance between two regions on the basis of neighbourhood relations as follows. Search for the shortest sequence of steps, where each step connects one region with one of its neighbours, that connects the two regions $q$ and $\tilde{q}$ with each other. The distance $d(q, \tilde{q})$ is given as the number of steps in this sequence. The distance between two firms $n$ and $\tilde{n}$ is given by $d(n, \tilde{n})=d\left(q_{n}, q_{\tilde{n}}\right)$. The average distance between employees of industry $i$ is then given by

$$
d_{i}(t)=\frac{\sum_{\substack{n \in \mathcal{N}(t) \\ i_{n}=i}} \sum_{\substack{\tilde{n} \in \mathcal{N}(t) \\ i_{\tilde{n}=i}}}\left[L_{n}(t) \cdot L_{\tilde{n}}(t) \cdot d(n, \tilde{n})\right]}{\sum_{\substack{n \in \mathcal{N}(t) \\ i_{n}=i}} \sum_{\substack{\tilde{n} \in \mathcal{N}(t) \\ i_{\tilde{n}}=i}}\left[L_{n}(t) \cdot L_{\tilde{n}}(t)\right]}
$$

while the average distance between the employees of different industries is given by

$$
d_{i \tilde{i}}(t)=\frac{\sum_{\substack{n \in \mathcal{N}(t) \\ i_{n}=i}} \sum_{\substack{\tilde{n} \in \mathcal{N}(t) \\ i_{\tilde{n}}=\tilde{i}}}\left[L_{n}(t) \cdot L_{\tilde{n}}(t) \cdot d(n, \tilde{n})\right]}{\sum_{\substack{n \in \mathcal{N}(t) \\ i_{n}=i}} \sum_{\substack{\tilde{n} \in \mathcal{N}(t) \\ i_{\tilde{n}}=\tilde{i}}}\left[L_{n}(t) \cdot L_{\tilde{n}}(t)\right]} .
$$

In the case of two industries we obtain three distances, $d_{1}, d_{2}$ and $d_{12}$, as dependent variables.

To study the relation between the dependent and independent variables, we again conduct simulation experiments. For each of the independent variables three values are chosen: $s_{n, i}=\frac{1}{24}, \frac{1}{9}, \frac{1}{3}, p_{N, i}=0.01,0.02,0.08, L_{q, \text { other }}=100$, 1000, 10000, and $s_{i j}=\frac{1}{9}, \frac{2}{9}, \frac{1}{3}$. For each combination of these parameters (all other parameters are set to their standard value) one simulation is run and the distance measures are calculated after 2000 steps. A multiple regression is then conducted for each distance measure with all parameters, their logarithms, and their products of second order as independent variables. All significant independent variables and the respective results of the regression are listed in Table 4.

These results reveal several interesting aspects. First, all three dependent measures are not well explained by the regression results $\left(R^{2}\right.$ is approximately one half). This is mainly due to the high fluctuations of the results for each parameter set which are caused by the strong dependence on single random events (cf. the discussion of path-dependency above). Second, the results for $d_{1}$ and $d_{2}$ are nearly identical, which should be expected since both industries are characterised 


\begin{tabular}{|c|c|c|c|}
\hline & $d_{1}$ & $d_{2}$ & $d_{12}$ \\
\hline$L_{q, \text { other }}$ & & & $0,13135^{*}$ \\
\hline $\ln \left(\eta_{q}\right)$ & $-0,1947^{*}$ & & \\
\hline $\ln \left(s_{i j}\right)$ & $0,24406^{*}$ & $0,29153^{*}$ & $-0,57965^{*}$ \\
\hline $\ln \left(L_{q, o t h e r}\right)$ & $-0,41564^{* * *}$ & $-0,36228^{* * *}$ & $-0,37086^{* *}$ \\
\hline$p_{N, q} \cdot \eta_{q}$ & & $-15,61138^{*}$ & $42,98076^{* * *}$ \\
\hline$p_{N, q} \cdot L_{q, o t h e r}$ & $1,08222^{* *}$ & $1,10365^{* * *}$ & \\
\hline$\eta_{q} \cdot L_{q, o t h e r}$ & $0,18518^{*}$ & & \\
\hline$L_{q, \text { other }} \cdot s_{i j}$ & & $-0,49465^{*}$ & \\
\hline adjusted $R^{2}$ & 0.51274 & 0.54989 & 0.49773 \\
\hline
\end{tabular}

Table 4: Regression factors for all significant independent variables $\left(^{*}=\right.$ significant at 0.1 , ${ }^{* *}=$ significant at $0.01,{ }^{* * *}=$ significant at 0.001$)$.

by the same parameters in the simulations. The results for $d_{1}$ and $d_{2}$ differ only with respect to those independent variables that are not significant at 0.01 . Thus, we restrict the following discussion on the variables that are significant at least at a level of 0.01 , since the other results seem not to be reliable.

Third, the industrial concentration depends only on the value of $L_{q, o t h e r}$ and a combination of this value and the likelihood of spin-offs in neighbouring regions. Technological spillovers to neighbouring regions do not play a significant role for the degree of industrial concentration. The value of $L_{q, \text { other }}$ influences the industrial concentration in a logarithmic way in the direction that was also found above.

Fourth, the distance between the two industries decreases similarily with the logarithm of $L_{q, o t h e r}$. The more the local wages react on the number of employees of one industries, the more other industries avoid the same region. Furthermore, the distance between the two industries depends on the two new processes, determined by the values $\eta_{q}$ and $p_{N, q}$. The higher their product, the further away from each other do the industries locate. Both parameters have a similar effect on the spatial distribution of an industry. If one region contains a high number of firms of one industry, the neighbouring regions are likely to be populated by the same industry if $\eta_{q}$ and $p_{N, q}$ are large. As a consequence, the other industry is less likely to locate in a neighbouring region and the distance between the industries increases.

\section{Conclusion}

This paper presents a first step towards the study of the evolution of industrial clusters with the help of simulations. Many aspects have still be handled in a 
simplifying manner. Nevertheless, some insights have been obtained. First, it has been found that the spatial structure locks in, independent of the parameters chosen. Second, these lock-ins do in many cases not relate to the existence of a stable spatial distribution of industrial activity. Instead, the dynamics show a strong path-dependence which includes in many cases also the structure of the spatial distribution. Third, the simulations reveal some circumstances that should increase or decrease the degree of spatial concentration of an industry.

Nevertheless, this approach can and will be expanded with respect to several aspects. First, in this approach no interactions between regions took place. A more natural approach should be based on a two-dimensional cellular automaton where neighbouring regions interact with each other. Second, the processes within the regions should be modelled in more detail. Especially, the process of innovation, the influence of public research institutions, infrastructure, and politics, and the labour market are planned to be modelled in more detail. Finally, the results of the simulations should be tested and compared with empirical data. Some of this is planned to be done in further projects, some of it might be taken up by other researchers.

\section{References}

Allen, P. M. (1997a). Cities and Regions as Evolutionary, Complex Systems. Geographical Systems 4, 103-130.

Allen, P. M. (1997b). Cities and Regions as Self-Organizing Systems. Models of Complexity. Amsterdam: Gordon and Breach.

Audretsch, D. B. (1998). Agglomeration and the Location of Innovative Activity Oxford Review of Economic Policy 14, 18-29.

Becattini, G. (1990). The Marshallian Industrial District as a Socio-economic Notion. In: (Pyke, F., Becattini, G. and Sengenberger, W., Eds.) Industrial Districts and Inter-firm Cooperation in Italy, pp. 37-51. Geneva: International Institute for Labour Studies.

Brenner, T. (2000). Industrial Clusters and Milieux: A Typology from an Evoluationary Perspective. mimeo, Jena.

Camagni, R. P. (1995). The Concept of Innovative Milieu and Its Relevance for Public Policies in European Lagging Regions. Papers in Regional Science 74, 317-340.

Camagni, R. P. \& Diappi, L. (1991). A Supply-oriented Urban Dynamics Model with Innovation and Synergy Effects. In: (Boyce, D. E., Nijkamp, P. and Shefer, D. ,Eds.) Regional Science, pp. 339-357. Berlin: Springer-Verlag.

Caniëls, M. C. J. and Verspagen, B. (1999). Spatial Distance in a Technology Gap Model. Working Paper 99.10, Eindhoven Centre for Innovation Studies.

Dalum, B. (1995). Local and Global Linkages: The Radiocommunications Cluster in Northern Denmark. mimeo, Aalborg University.

Dei Ottati, G. (1994). Cooperation and Competition in the Industrial District as an Organisation Model European Planning Studies 2, 463-483.

Ellison, G. and Glaeser, E. L. (1994). Geographic Concentration in U.S. Manufacturing Industies: A Dartboard Approach. Working Paper No. 4840, National Bureau of Economic Research.

Jaffe, A.B., Trajtenberg, M. and Henderson, R. (1993). Geographic Localization of Knowledge Spillovers as Evidenced by Patent Citations Quarterly Journal of Economics 79, 577-598.

Jonard, N. and Yildizoglu, M. (1998). Technological Diversity in an Evolutionary Industry Model with Localized Learning and Network Externalities. Structural Change and Economic Dynamics 9, 35-53.

Krugman, P. (1991a). Geography and Trade. Cambridge: MIT Press.

Krugman, P. (1991b). Increasing Returns and Economic Geography. Journal of Political Economy 99, 483-499.

Lawson, C (1997). Territorial Clustering and High-Technology Innovation: From Industrial Districts to Innovative Milieux. Working Paper No. 54, ESRC Centre for Business Research, University of Cambridge

Maillat, D. and Lecoq, B. (1992). New Technologies and Transformation of Regional Structures in Europe: The Role of the Milieu. Entrepreneurship \& Regional Development 4, 1-20. 
Markusen, A. (1996). Sticky Places in Slippery Space: A Typology of Industrial Districts. Economic Geography 72, 293-313.

Matsuyama, K. and Takahashi, T. (1998). Self-Defeating Regional Concentration. Review of Economic Studies 65, 211-234.

Pyke, F. and Sengenberger, W., Eds (1992). Industrial Districts and Local Economic Regeneration. Geneva: International Institute for Labour Studies.

Rabellotti, R. (1997). External Economies and Cooperation in Industrial Districts. Houndmills: Macmillan Press Ltd.

Rosegrant, S. and Lampe, D. R. (1992). Route 128. Basic Books.

Saxenian, A.-L. (1994). Regional Advantage. Cambridge: Harvard University Press.

Schweitzer, F. (1998). Modelling Migration and Economic Agglomeration with Active Brownian Particles. adv. complex systems 1, 11-37.

Scott, A. J. (1992). The Role of Large Producers in Industrial Districts: A Case Study of High Technology Systems Houses in Southern California. Regional Studies 26, 265-275.

van Dijk, M. P. (1995). Flexible Specialisation, The New Competition and Industrial Districts. Small Business Economics 7, 15-27.

Winer, B. J. (1971). Statistical Principles in Experimental Design. New York: McGraw-Hill.

Witt, U. (1986). Firms' Market Behavior Under Imperfect Information and Economic Natural Selection. Journal of Economic Behavior and Organization 7, 265-290. 